\title{
An Exceptional Case of Spontaneous Fistulization of an Intrahepatic Biliary Cyst in to the Colon, Operated Tikur Anbessa Specialized Hospital, Ethiopia - A Case Report
}

\author{
Nebyou Seyoum, Feron Getachew \\ ${ }^{1}$ Department of surgery, Tikur Anbessa Specialized Hospital, Addis Ababa \\ University, Addis Ababa, Ethiopia.
}

Correspondence to: Nebyou Seyoum, mail: nebyouss@yahoo.com

https://dx.doi.org/10.4314/ecajs.v22i1.16

\begin{abstract}
Biliary cysts are congenital cystic dilatations of the extrahepatic and/or intrahepatic biliary tree. Intrahepatic cysts constitute less than $1 \%$ of the biliary cysts. Complications of these cysts include cholangitis, livercirrhosis, liver abscess andcholangiocarcinoma. In intrahepatic cysts the complications can also be related to compression of adjacent viscera, infection of the cyst's contents or perforation of the cyst. Spontaneous fistulization of a biliary cyst into hollow abdominal organsis a rare complication. We report an exceptionalcase in whom an intrahepatic biliary cyst spontaneouslyfistulized into hepatic flexure of the colon. Patient presented to our hospital with 02 months history of abdominal pain, weight loss, and 02 weeks of jaundice. Thecommunication with colon was diagnosed by CT scan before surgery. But, surgical intervention was required for the complete diagnosis. Postoperatively, patientrecovery was uneventful.
\end{abstract}

Keywords: Biliary cyst. Colon.Spontaneous Fistula. Caroli'sdisease. Intrahepatic

\section{Introduction}

Caroli's disease refers to Todani $V$ biliary cysts which are rare congenital cystic dilatations that involve only the intra hepatic bile ducts ${ }^{1-4}$. They are caused byan anomalous rearrangement of the embryonic ductal plate.[5,6]lf the defective remodeling involves the larger intrahepatic ducts Caroli's disease develops.But, when the entire intrahepatic biliarytree is involved the condition is designatedCaroli's syndrome;in which there is an associated congenital hepatic fibrosis ${ }^{5-7}$. Unlike other types of biliary cysts, Caroli's disease rarely present in childhood and the diagnosis is usually made at an advanced age $\mathrm{e}^{8-10}$. Biliary cysts are associated with significant complications such as stone formation, cholangitis, secondary biliary cirrhosis and rupture ${ }^{2,11}$. Spontaneous biliary colonic fistulas are rare. Whenever they occur, usually, areassociated with diseases of extrahepatic biliary tree ${ }^{12-14}$. Spontaneousfistulization of a solitary intrahepatic biliary cyst intoa transverse colonis extremely rare and has not been previously reported to the best of our knowledge.

We hereby, describe a case of a solitary intrahepatic biliary cyst with spontaneous fistulization into hepatic flexure of the colon. Diagnosis posed achallenge. Written informed 


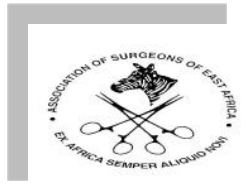

consent was obtained from the patient for publication of this case report and accompanying images.

\section{Case Presentation}

A 53 years old male was admitted to our hospital with 02 months history of gradually developed mild, right sided, dull aching, upper abdominal, pain which is not relatedto ingestion of any form of meal. He has also history of associatedlow grade intermittent fever, fatigue, jaundice which lasted for two weeks, and infrequent loose stool. The jaundice had no obstructive features.Before presentation to us, he was treated with unspecified oral medications by a GP, at a general hospital. But, he showed no improvement. Otherwise he has no history oftrauma, previous surgery or other known medical illness, no history sheep rearing. Physical examination revealed the patient was pale and emaciated. On abdominal examination, he had mild right upper quadrant tenderness; otherwise normal. There were no signs of peritonitis. Per rectal digital examination stained the finger with brownish faecal matter. He had no signs of anaphylaxis.

His Laboratory investigation results are as follows: Hemoglobin $=8.4 \mathrm{gm} / \mathrm{dl}$, Hematocrit $=24.9 \%, W B C$ and platelet count are within the normal range. Liver function test: $\mathrm{SGPT}=557$, Albumin $=2.8$, otherwise normal. Electrolytes were within normal limits. ERCP and MRCPwere not available. The preliminary ultrasound examination (figure 1) showeda thin-walled heterogeneous complex cystic lesion in the right hepatic lobe withmaximum diameter of $12 \mathrm{~cm}$.Liver appeared normal, with no other parenchymal lesion. Gall bladder had normal size and wall thickness. Based on the above findings, CT scan of the abdomen was performed and revealed $13 \times 11 \mathrm{~cm}$ measuring right hepatic cyst with air fluid level, which extends into the right subphrenicspaceresulting in elevation ofthe diaphragm. (Figure 2) There was also adjacent right hepatic flexure colonic thickening and abnormal contrast enhancement (Figures 3b \& 3c). But, no clear evidence of bile duct dilatation. (Figures 3ac) Gall bladder was contracted with wall enhancement. The kidneys appeared normal.
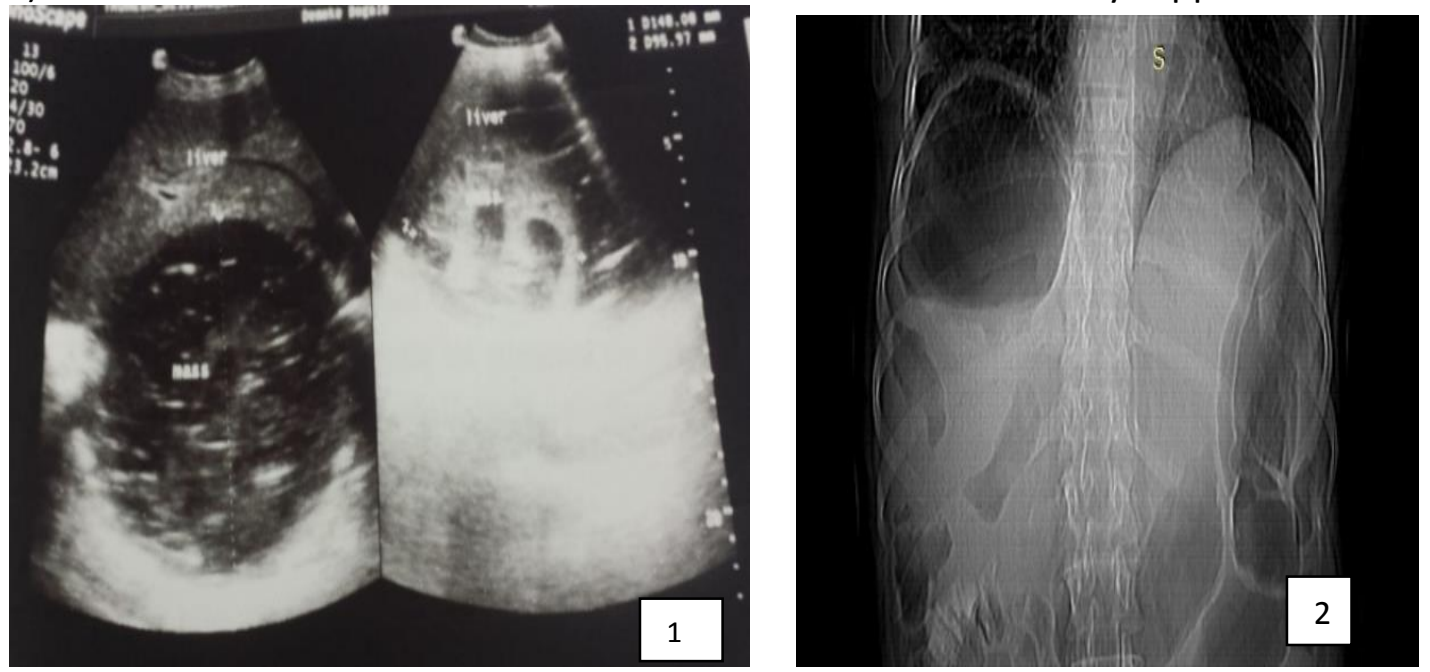

Figure 1(Left): Abdominal US shows thin walled, heterogeneous complex cyst in theright hepatic lobe.

Figure 2 (Right): Scout film showsright subphreniccollection with air fluid level (found later 


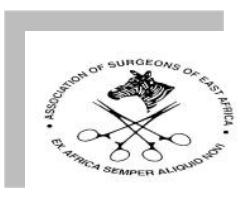

to be an extension from the intrahepatic cyst)
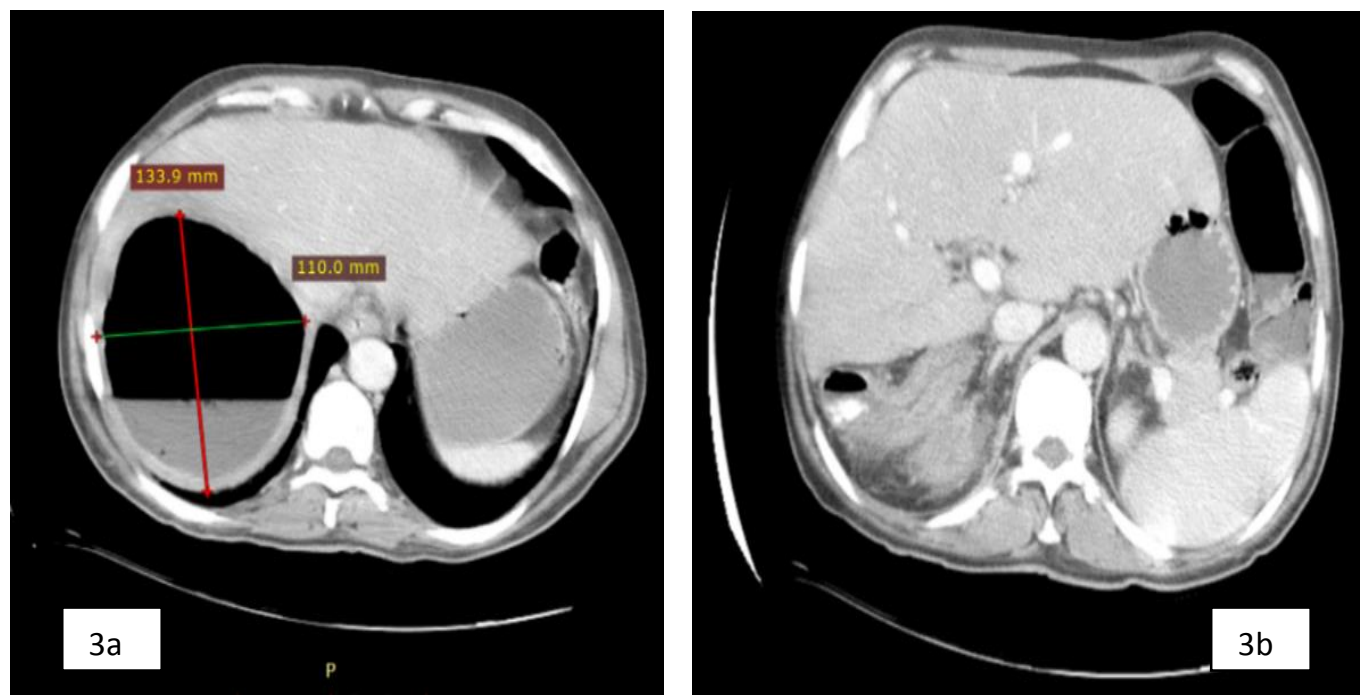

Figure 3. CT scan: Shows posteriorly located, huge peripheral hepatic cyst with air fluid level (Fig.3a), the colo-cystic fistula with significant colonic thickening and surrounding inflammation is demonstrated. (Figures $3 \mathrm{~b}$ and $3 \mathrm{c}$ )
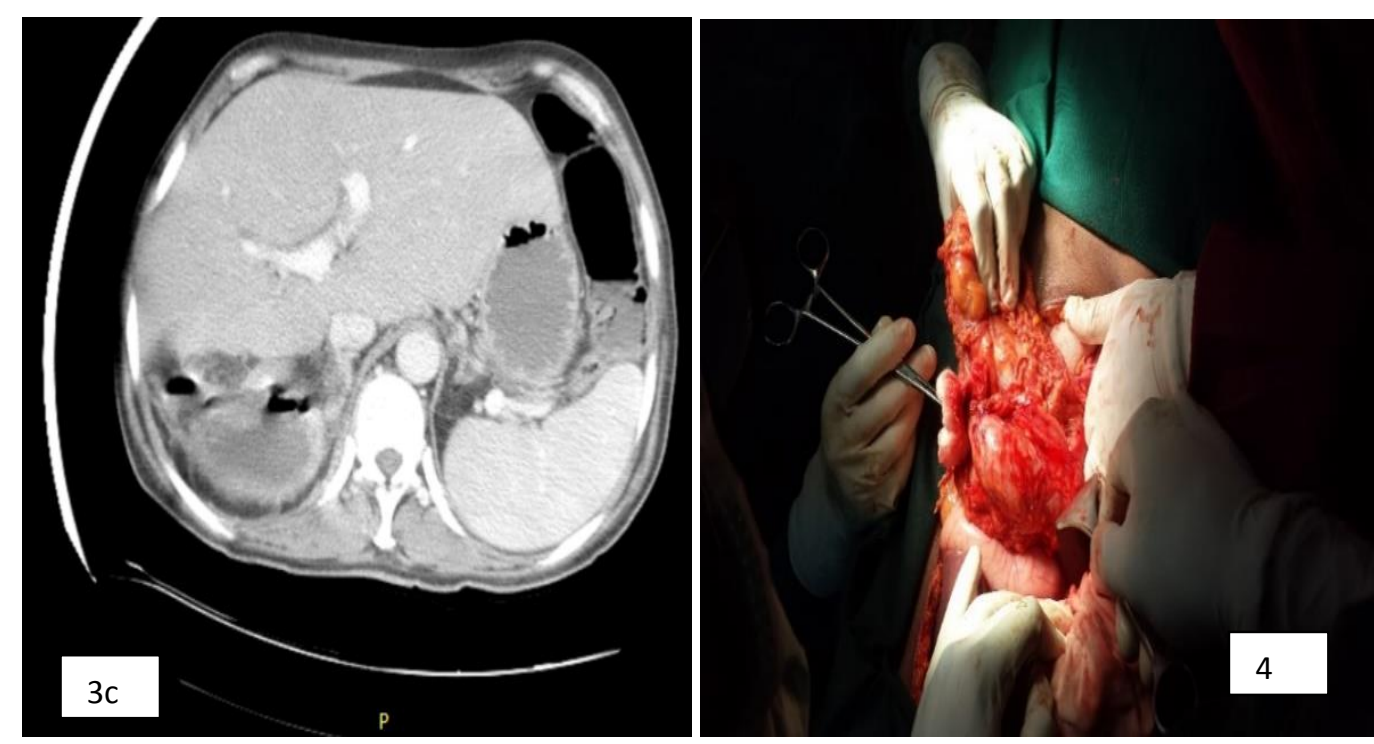

Figure 4(right): Intraoperative picture: cystdrained and resection was undergoing

The patient was taken to the operation theater for exploratory laparotomy, which revealed attachment of right extreme end of the colon to segment six of the liver. There was an opening in the colon which communicates with a bile containing cavity, in the liver.Extrahepatic bile ducts were normal. Colon disconnected, bile aspirated, and segment of the colon resected. There were no features of malignancy. End to end anastomosis of the colon and omentoplastyof the cystic cavity in the liver was done. Sub hepatic drain was left. 
Biopsy was taken and its' result shows localized organizing fibrino-purulent serositis of the hepatic colonic flexure with suggestion to look for hepatic or biliary lesion. Unfortunately, we were not able to retrieve cyst wall biopsy. The sub hepatic drainhad minimal output of serosanginious fluid, which later stopped and removed on the third day.Postoperatively patienthad good recovery and discharged uneventfully.

\section{Discussion}

Biliary cysts, aka Choledochal cysts, are rare congenital cystic dilatations of the extrahepatic and/or intrahepatic biliary tree that affect females (three to eight times) more often than males ${ }^{1,2}$. Although frequently diagnosed in infancy or childhood, significant number of patients have reached adulthood when diagnosed ${ }^{1,2}$. Less than one half of patients clinically present with the classic clinical triad of right upper quadrant abdominal pain, jaundice, and a mass ${ }^{1}$. In adults, this triad is unusual, and abdominal pain with tenderness is usually the only initial feature ${ }^{2,15}$; as it is in our patient. The cause is not clearly known.

Different authors proposed variable classification systems for biliary cysts ${ }^{16,17,3,4 .}$ Among which, despite its drawback, the modified Todani classification is the widely used one ${ }^{3,4}$. According to Todani, type I to type IV biliary cysts all involve the extrahepaticbiliary tree (type IVa: multiple intra-and extrahepatic bile ducts). Type $\mathrm{V}$ cysts represent single or multiple intrahepatic bile duct cysts, without extrahepatic involvement. This condition (presence of type $\mathrm{V}$ biliary cyst) is called Caroli's disease and when associated with congenital hepatic fibrosis it is termed Caroli's Syndrome. ${ }^{18,19}$. In our case, the presence of a single bile containing intrahepatic cyst in the absence of extrahepatic biliary tree involvement and in the absence features of hepatic fibrosis(even though not biopsy proven) suggests simple Caroli's disease.Although present from birth,

Caroli's disease usually remains asymptomatic during the first 20 years, and may also remain so throughout life ${ }^{18}$. Unlike other biliary cysts, it rarely present in childhood and the diagnosis is usually made at an advanced age ${ }^{19-22}$. Our patient was 53 years old when diagnosed and he had single lobeinvolvement. Fteriche and colleagues ${ }^{23}$ reported 16 cases of Caroli'sdisease, which showed findings similar to our patient's, in age distribution and lobe involvement. The mean age was 55 years and the distribution of biliary lesions was monolobar in 13 patients. In patients like ours, the isolated monolobar form of disease, the absence of hepatic fibrosis and its complications, as well as the absence of cholelithiasis and absence of previous episodes of cholangitis could be possible explanations for the late presentation. Cholangitis, pancreatitis, hepatic fibrosis, and malignancy have all been reported at the time of presentation ${ }^{2,5,8-11}$.

The presence of anemia and cachexia in our patient may suggest possible malignancy. The jaundice probably resulted as consequence of cholangitis. Other complications of the diseaseincludeintra- and extra hepatic lithiasis. Even though unusual, acute rupture of the cyst resulting in biliary peritonitis can also occur ${ }^{2}$. Though not common, spontaneous fistulizationinto an adjacent hollow viscous organ (like duodenum, colon, stomach etc.) is also a known complication ofbiliary cysts ${ }^{13,24}$. It comprises only $<1 \%$ of all biliary disorders ${ }^{12}$. 
Extrahepatic biliary cysts areusually responsible for such fistula, the commonest type beingcholecysto-entericfistula $(75-85 \%)^{12,25}$.

Spontaneous biliary colonic fistulas are rare. Whenever they occur, usually, are associated with diseases of extrahepatic biliary tree ${ }^{12-14,26}$. Biliary calculus disease is responsible for such fistulasin up to $90 \%$ ofcases ${ }^{13}$. Patients can present with variable nonspecific signs and symptoms, posing a challenge to early diagnosis ${ }^{27}$. Despite presence of biliary-colonic fistula, patients can also be asymptomatic ${ }^{28}$. Fistulization of an intrahepatic biliary cyst in to a transverse colonis extremely rare and has not been previously reported to the best of our knowledge.

In the present case, imaging and operative findings combined revealed a bile containing, single, intrahepatic (biliary) cyst with normal extrahepatic bile ducts, gallbladder and liver parenchyma; These suggest an intrahepatic biliary cyst(Caroli's disease). There were no typical features of hydatid disease, which is one of the known causes of intrahepatic cysts in endemic areas, such as ours (East Africa) ${ }^{29}$. Magnetic resonance or Endoscopic retrograde cholangiopancreatographycould have been the choice of modality to define the details of the biliary-colonic fistula, if the facility would have been there.In our case, the CT scan showing presence of air under the diaphragm and inside the cyst cavity along with colonic wall thickening confirmed the communication between the cyst cavity and colon, even before surgical intervention. [Figure 2,3a-c] Initially, it was difficult to safely define the origin of the cyst,due topresence of deceiving features like extension in to subdiaphrgmatic space and absence of obvious intrahepatic bile duct dilatation. The complete diagnosis was undoubtedly made after surgery.

The perforation of the cyst into the transverse colon can occur due to primary pathology of the colonor secondary to infection of the cyst with inflammation and swelling of its wall giving rise to adhesion formation between the cyst and the surrounding organs. Continuous mechanical friction in a cyst with thick or calcified wall can result in colo-cystic fistula by progressivelyeroding the hollow viscous wall, as it is seen in conditions like hydatid cyst. But, sincethere is no significant cyst wall thickening or calcification (shown on abdominal ultrasound [Figure 1] ) and colonic biopsy report came negative (with suggestion of hepatic or biliary cause), infection of the cyst resulting in surrounding inflammation [3b \&3c]could be the most probable cause in the presented case.The presence of fever could be the manifestation ofinfection. The content of the cyst did not drain into the large bowel because the fistula was very narrow and allowed only gas from the colon to pass into the cyst.

Other differential diagnosis like non-parasitic hepatic cysts (NPHC) and simple hepatic cysts could have been considered in the differential diagnosis but the complex, heterogeneous and bilious content of the cyst makes them less likely.

\section{Conclusion}

Biliary-colonicfistulas are rare but known complications ofbiliary cysts, usuallyoccurring in extra hepatic biliary ducts/cysts. However, our patient represents an exceptionally rare case 
of biliary cyst fistulization as he presented with spontaneous communication between intrahepatic biliary cyst and hepatic flexure of the colon.On top of that the usual biliary duct dilatation was not seen; ratherit was an isolatedbiliary cyst.The fistula also occurred without associated biliary calculus. Although, the fistulawas initially revealed by CT scan, surgery was required to reach in to a complete diagnosis. The outcome of surgical intervention was satisfactory.

\section{References}

1. Brunicardi, F Charles; Andersen, Dana K; Billiar, Timothy R; Dunn, David L; Hunter, John G; Thai, Pham H. chapter 32. Gall baldder and the extrahepatic biliary system. In Schwartz's principles of surgery $10^{\text {th }}$ edition.NewYork:McGraw-Hill Education,2014:1330

2. $D^{\prime}$ Angelica M, Fong Y: From the biliary system. Sabiston Textbook of Surgery. 19th edition. Edited by: Townsend C, Beauchamp D, Evers M, Mattox K. Elsevier, Saunders; 2012:1503-1505, 1447

3. Todani T, Watanabe Y, Narusue M, Tabuchi K, OkajimaK.Congenitalbie duct cysts: Classification, operative procedures, and review of thirty-seven cases including cancer arising from choledochal cyst. Am J Surg. 1977; 134:263-269

4. Todani T, Watanabe $Y$, Toki A, Morotomi Y. Classification of congenital biliary cystic disease: specialreference to type Ic and IVA cysts with primary ductal stricture. J HepatobiliaryPancreat Surg. 2003; 10; 340-344.

5. Desmet VJ. Pathogenesis of ductal plate malformation. J GastroenterolHepatol 2004; 19: S356-S360

6. Sherlock S, Dooley J. Diseases of the liver and billiary system.11th ed. Milano: Blackwell Sci Pub, 2002: 583

7. DesmetVJ.What is congenital hepatic fibrosis? Histopathology 1992; 20:465

8. Tsuchida $Y$, Sato $T$, Sango K, et al. Evaluation of long-term results of Caroli's disease: 21 years observation of a family with autosomal "dominant" inheritance, and review of the literature. Hepatogastroenterology 1995; 42:175-181

9. Keramidas DC, Kapouleas GP, Sakellaris G. Case Report. Isolated Caroli's disease presented as an exophytic mass in the liver. PedSurgInternat 1998; 13:177-179

10. Fagundes-Neto U, Schettini ST, Wehba J, Pinus J, Patricio FR. Caroli's disease in childhood: report of two new cases. J PediatrGastroenterolNutr 1983; 2:708-711.

11. Ludmil M. Veltchev, Manol A. Kalniev, Todor A. Todorov. BILE DUCT SYSTEM Malformation -Embryological and Pathological Association. Treatment /Review Article/ journal of IMAB - Annual Proceeding (Scientific Papers) 2009, book 1; 66-67

12. Glenn F, Reed C, Grafe WR, Biliary enteric fistulas. SurgGynecolObstet 1981; 153:527-31.

13. Piedad OH, Wels PB. Spontaneous internal biliary fistula, obstructive and nonobstructive types. Twenty-year review of 55 cases. Ann Surg 1972; 175: 75-80

14. AAnees, M Khan, I Zea, M Khalid. Choledocho-colonic fistula: A Rare Biliary-Enteric Fistula Causing Refractory Diarrhoea. The Internet Journal of Surgery. 2007 Volume 17 Number 2. 
15. Singham J, Yoshida EM, Scudamore $\mathrm{CH}$. Choledochal cysts: classification and pathogenesis. J Can Chir 2009; 52:437-438.

16. Alonso-Lej F, Rever WB Jr, Pessagno DJ. Congenital choledochal cyst with a report of 2 and analysis of 94 cases. IntAbstrSurg 1959; 108:1-30.

17. T. G. Mofokeng, R. BARRY, O. C. Buchel .Cystic lesions of the biliary tree: Proposal for arevised classification system .SAJS. November 2011 Vol 49, NO. 4,

18. Yonem O, Bayraktar Y. Clinical characteristics of Caroli's disease. World J Gastroenterol 2007; 13(13): 1930-1933]

19. MeropiTzoufi , Maria Rogalidou , EcateriniDrimtzia , IriniSionti , IliadaNakou ,Maria Argyropoulou, Epameinondas V. Tsianos , Antigone Siamopoulou-MavridouCaroli's disease: Description of a casewith a benign clinical course. Annals of Gastroenterolgy 2011; 24 (2): 129-133

20. Tsuchida Y, Sato T, Sango K, et al. Evaluation of long-term results of Caroli's disease: 21 years observation of a family with autosomal "dominant" inheritance, and review of the literature. Hepatogastroenterology 1995; 42:175-18

21. Keramidas DC, Kapouleas GP, Sakellaris G. Case Report. Isolated Caroli's disease presented as an exophytic mass in the liver. PedSurgInternat 1998; 13:177-179.

22. Fagundes-Neto U, Schettini ST, Wehba J, Pinus J, Patricio FR. Caroli's disease in childhood: report of two new cases. J PediatrGastroenterolNutr 1983; 2:708-711.

23. The Caroli'sdisease.Report of 16 cases. Fteriche F, Makin A, Ksantini R, Rebai W, BediouiH,Nouira K, Daghfous A, Ayadi S, Chebbi F, Jouini M, Ammous A, MontassarKacem J, Ben Safta Z. Tunis Med.2012 Aug-Sep; 90(8-9): 630-635.

24. HarkinM, Boyd R, Stricoff R, Shaftan G, Saxe A Am Surg 1997; 63:472-4

25. Le Blanc KA. Spontaneous biliary-enteric fistulas. South Med J 1983; 76: 1249-1252.

26. Rawas MM, Yee AC, Ho CS. Choledochocolonic fistula-a rare complication of cholangiocarcinoma. Can AssocRadiol J 1987; 38: 139-40

27. Ibrahim IM, Wolodiger F, Saber AA, DenneryB.Treatment of cholecystocoloic fistula by laparascopy.SurgEndosc 1995; 9:728-9.

28. Varma P, Tam A, Fanning SB, Mitchell BL (2016). The Asymptomatic Spontaneous Biliary-Colonic Fistula. JSM GastroenterolHepatol 4(2): 1056

29. KasperD, FauciA, Hausser S, LongoD, JamesonL and Losacalzo J , Harrison's principles of internal medicine $.19^{\text {th }}$ edition volume 1 . New York. McGraw Hill, Medical Pub.Division. 2015; 1432 